\title{
Complexo Econômico Industrial da Saúde: os reflexos jurídicos dos estímulos ao desenvolvimento tecnológico previstos na Lei no $13.243 / 2016$
}

Industrial Health Economic Complex: the legal repercussions of the incentives for technological development provided for in Law no $13.243 / 2016$

Complejo Económico Industrial de la Salud: los reflejos jurídicos de los estímulos al desarrollo tecnológico previstos en la Ley nํㅜ 13.243/2016

RESUMO. Objetivo: O artigo apresenta quais foram os reflexos jurídicos decorrentes dos estímulos ao desenvolvimento tecnológico, previstos na Lei no $13.243 / 2016$, no fomento do Complexo Econômico Industrial da Saúde. Metodologia: Pesquisa exploratória descritiva, com base documental e bibliográfica, utilizando dados primários disponibilizados no banco de dados do Ministério da Saúde e secundários apresentados em artigos. Resultados: Os estímulos previstos na Lei no $13.243 / 2016$ refletiram de forma positiva no fomento do Complexo. Conclusão: As disposições da Lei no 13.243/2016 exerceram influência positiva no fomento do setor produtivo da saúde, a partir da flexibilização na contratação, na formalização de parcerias com o setor produtivo da saúde, bem como, a alocação de recursos para desenvolvimento de tecnologia ou inovação tecnológica são aspectos relevantes para o fomento do Complexo Econômico Industrial da Saúde.

Palavras-chave: Desenvolvimento Tecnológico. Pesquisa Científica e Desenvolvimento Tecnológico. Investimentos em Saúde. Inovação.

ABSTRACT. Objective: The article presents the legal consequences of stimulating technological development, provided for in Law 13,243 / 2016, in the promotion of the Economic Industrial Health Complex. Methodology: Research descriptive exploratory, based on documentary and bibliographical, using primary data made available in the database of the Ministry of Health and secondary presented in articles. Results: The incentives provided for in Law 13243/2016 reflected positively in the development of the Complex. Conclusion: The provisions of Law No. 13243/2016 have had a positive influence on the promotion of the health productive sector, through flexibilization in contracting, in the formalization of partnerships with the productive sector of health, as well as the allocation of resources for the development of technology or technological innovation are relevant aspects for the promotion of the Economic Industrial Health Complex.

Keywords: Technological Development. Scientific Research and Technological Development. Investments. Innovation.

RESUMEN. Objetivo: El artículo presenta cuáles fueron los reflejos jurídicos derivados de los estímulos al desarrollo tecnológico, previstos en la Ley no 13.243 / 2016, en el fomento del Complejo Económico Industrial de la Salud. Metodología: Investigación exploratoria

\footnotetext{
${ }_{1}^{1}$ Advogada. Consultora Técnica Jurídica do Ministério da Saúde. Secretaria de Ciência, Tecnologia e Insumos Estratégicos, Departamento do Complexo Industrial e Inovação em Saúde. E-mail: silvia.amalper@gmail.com
} 
descriptiva, con base documental y bibliográfica, utilizando datos primarios disponibilizados en el banco de datos del Ministerio de Salud y secundarios presentados en artículos. Resultados: Los estímulos previstos en la Ley no 13.243 / 2016 reflejaron de forma positiva en el fomento del Complejo. Conclusión: Las disposiciones de la Ley no 13.243 / 2016, ejercieron una influencia positiva en el fomento del sector productivo de la salud, a partir de la flexibilización en la contratación, en la formalización de alianzas con el sector productivo de la salud, así como la asignación de recursos para desarrollo de tecnología o innovación tecnológica son aspectos relevantes para el fomento del Complejo Económico Industrial de la Salud.

Palabras-Ilave: Desarrollo Tecnológico. Investigación Científica y Desarrollo Tecnológico. Inversiones en Salud. Innovación.

\section{Introdução}

Este artigo descreve quais são os reflexos jurídicos decorrentes dos estímulos ao desenvolvimento tecnológico previstos na Lei no 13.243/2016, e como influenciaram no fomento do Complexo Econômico Industrial da Saúde (CEIS).

Para compreender os impactos e efeitos no fomento do CEIS, faz-se necessário registrar que o Complexo Econômico Industrial da Saúde contempla toda a base produtiva e inovativa da saúde, envolvida na prestação do serviço, promoção e vigilância em saúde, o segmento secundário da economia, a exemplo das indústrias de base química, biotecnológica, mecânica e de materiais, e o terciário, referente aos serviços prestados nos estabelecimentos de saúde. (1)

Embora a saúde se configure como um direito social, elemento essencial do Estado de Bem-Estar Social na perspectiva da economia, por contar com uma base produtiva dinâmica e inovativa de bens e serviços, também pode ser considerada como um bem econômico com acumulação de capital. (2)

O fato da saúde ser compreendida como um bem econômico e social, está aliado à potencialidade do complexo de mobilizar tecnologias relevantes que possibilitam a inserção competitiva do país no contexto da econômica global, bem como, da área da saúde na pauta do desenvolvimento nacional. (1)

Ao que concerne à teoria da inovação, esta foi desenvolvida com base na observação das mudanças tecnológicas na produção industrial, basicamente, na de medicamentos e equipamentos de saúde. Sistemas complexos, que demandam crescentes investimentos em capacitação, pesquisa, desenvolvimento e inovação, a fim de se obter casos de inovações exitosas. (5) 
Portanto, a inovação na área da saúde contempla estudo de excelência, o que demanda investimentos na infraestrutura da Ciência, Tecnologia e Inovação em SaúdeCT\&I/S articulada com a base industrial, promovendo e qualificando sua consolidação.

Cabe destacar que inovação na saúde não é tão somente o processo de inovar, mas sim, um processo político e social integrante do planejamento estratégico do país, com vistas à redução nacional da dependência de insumos para saúde produzidos no exterior, reforçando a economia política do país (6).

Neste contexto, em 12 de janeiro promulgou-se a Lei no 13.243/2016, que institui o novo Marco Legal da Ciência e Tecnologia e Inovação no país, o qual modifica nove outras leis anteriores que de alguma forma regulavam, em parte, a Ciência, Tecnologia e Inovação (C\&T, I) no país. (7)

Dentre as leis alteradas, este trabalho faz a abordagem das modificações ocorridas na Lei no 8.666/93 (14) e na Lei no 10.973/2004 (15). A primeira institui as normas para licitações e contratos da Administração Pública, e a última dispõe sobre os incentivos à inovação e à pesquisa científica e tecnológica no ambiente produtivo.

A Lei no 10.973/2004 trouxe significativos avanços na legislação ao permitir que pesquisadores acadêmicos tenham maior mobilidade para atuar em projetos empresariais de desenvolvimento. Além disso, garantiu maior flexibilidade para a alocação de recursos públicos em projetos de inovação e de parceria com o setor produtivo privado que visam o aumento da taxa de inovação no país, cenários até então praticamente inviáveis legalmente. (8)

No entanto, embora todos os avanços previstos na Lei de 2004 do incentivo à inovação, à pesquisa científica e tecnológica no ambiente produtivo, assim como, da autorização da efetiva atuação de pesquisadores acadêmicos em projetos empresariais de desenvolvimento, havia outros entraves a serem superados. (8)

O principal entrave para os avanços no âmbito da Ciência, Tecnologia e Inovação do país, estava vinculado a necessidade de ampliar a flexibilidade de integração com o setor privado. No entanto, tal pretensão esbarrava na Constituição Federal, que não disciplinava de forma específica a relação entre entes públicos e privados, principalmente, quanto a transferência de recursos. (23)

Para tanto, promulgou-se a Emenda Constitucional (EC) ำ 85, de 26 de fevereiro de 2015, que dentre suas disposições instituiu a promoção da inovação pela articulação entre 
entes públicos e privados de ciência e tecnologia (Instituição Científica, Tecnológica e de Inovação - ICT), criou um Sistema Nacional de Ciência, Tecnologia e Inovação, e ainda, permitiu a destinação de verbas públicas para instituições de fomento à pesquisa, assim como a contratação de bens e serviços por regimes simplificados. (23)

Considerando a nova redação dada pela EC no 85/2015, aos artigos $218^{2}$ e $219^{3}$ que compõem juntamente com os 219-A e 219-B, o Capitulo IV - DA CIÊNCIA, TECNOLOGIA E INOVAÇÃO, editou-se, após um longo processo de discussão, a Lei no 13.243/2016, com vistas a corrigir tais distorções e viabilizar os processos de inovação no país e de desburocratizar a parceria público-privado, incidindo no aumento da participação do setor produtivo em projetos de desenvolvimento em inovação no país. (8)

\section{Metodologia}

O artigo foi desenvolvido a partir de pesquisa exploratória descritiva, com base documental e bibliográfica, utilizando dados primários e secundários.

Considerando que o artigo versa sobre os reflexos da Lei $n^{0}$ 13.243/2016 nas alterações da Lei no 8.666/93 da Lei no 10.973/2004, e consequentemente no fomento do Complexo Econômico Industrial da Saúde, se fez primordial abordar incialmente seus

\footnotetext{
2 "Art. 218. O Estado promoverá e incentivará o desenvolvimento científico, a pesquisa, a capacitação científica e tecnológica e a inovação.

§ 1ํㅡ A pesquisa científica básica e tecnológica receberá tratamento prioritário do Estado, tendo em vista o bem público e o progresso da ciência, tecnologia e inovação.

§ 3o O Estado apoiará a formação de recursos humanos nas áreas de ciência, pesquisa, tecnologia e inovação, inclusive por meio do apoio às atividades de extensão tecnológica, e concederá aos que delas se ocupem meios e condições especiais de trabalho.
}

$\S$ 60 O Estado, na execução das atividades previstas no caput, estimulará a articulação entre entes, tanto públicos quanto privados, nas diversas esferas de governo.

$\S 7^{\circ} \mathrm{O}$ Estado promoverá e incentivará a atuação no exterior das instituições públicas de ciência, tecnologia e inovação, com vistas à execução das atividades previstas no caput." (NR)

3 "Art. 219.

Parágrafo único. O Estado estimulará a formação e o fortalecimento da inovação nas empresas, bem como nos demais entes, públicos ou privados, a constituição e a manutenção de parques e polos tecnológicos e de demais ambientes promotores da inovação, a atuação dos inventores independentes e a criação, absorção, difusão e transferência de tecnologia." (NR)

Art. 219-A. A União, os Estados, o Distrito Federal e os Municípios poderão firmar instrumentos de cooperação com órgãos e entidades públicos e com entidades privadas, inclusive para o compartilhamento de recursos humanos especializados e capacidade instalada, para a execução de projetos de pesquisa, de desenvolvimento científico e tecnológico e de inovação, mediante contrapartida financeira ou não financeira assumida pelo ente beneficiário, na forma da lei.

Art. 219-B. O Sistema Nacional de Ciência, Tecnologia e Inovação (SNCTI) será organizado em regime de colaboração entre entes, tanto públicos quanto privados, com vistas a promover o desenvolvimento científico e tecnológico e a inovação. $\S 1^{\circ}$ Lei federal disporá sobre as normas gerais do SNCTI.

$\S 2^{\circ}$ Os Estados, o Distrito Federal e os Municípios legislarão concorrentemente sobre suas peculiaridades. 
conceitos e formas de desenvolvimento, com vistas a possibilitar melhor compreensão das transformações geradas, sob a égide dessa nova Lei.

A descrição do CEIS foi subsidiada por artigos publicados no livro "Brasil Saúde de Amanhã: complexo econômico-industrial da saúde" da Editora Fiocruz (11) e os Volumes 1 e 2 do livro "Saúde, Desenvolvimento e Inovação" (4,5,9 e 10), os quais representam quase uma década dos estudos do Grupo de Pesquisa Inovação em Saúde da Fundação Oswaldo Cruz (GIS/Fiocruz).

No tocante a contextualização dos reflexos no fomento do Complexo Econômico Industrial da Saúde, oriundos da edição da Lei n 13.243/2016, o artigo se desenvolveu a partir da descrição de quais são as inovações propostas pela respectiva legislação, e de que maneira influenciaram o setor.

A partir do mapeamento das alterações na Lei $n^{0} 8.666 / 93$, foi possível abordar quais os impactos e efeitos destas modificações no fomento do CEIS, perpassando por teses e artigos focados na análise de compras governamentais, avalição e interesses estratégicos para incorporação de tecnologia em saúde (16) e formas de viabilizar tais incorporações.

Com base nas informações divulgadas no site do Ministério da Saúde (16), foi possível descrever quais e quantos processos de incorporação estão em desenvolvimento, respaldados pelo disposto na Lei n⒔243/2016 ou em decorrência de outra legislação por ela alteradas.

A pesquisa bibliográfica foi realizada nas bases de dados Biblioteca Virtual em Saúde (BVS) e Google Acadêmico utilizando a palavra-chave "Complexo Econômico-Industrial da Saúde”, no período de 2004 a 2017, e no idioma português. Totalizaram 28 publicações encontradas na BVS e aproximadamente 405 registros no Google Acadêmico, dos quais foram selecionados 02 e 04 publicações, respectivamente, pelo conteúdo afeto ao fomento de políticas públicas para o desenvolvimento do CEIS.

O artigo não foi submetido ao conhecimento e aprovação do Comitê de Ética em Pesquisa por não envolver o estudo com seres humanos.

\section{Resultados e Discussão}

Considerando o estudo realizado, é possível identificar que as disposições contidas na Lei no 13.243/2016, exerceram influência direta no fomento do sistema produtivo da saúde. 
O Sistema Produtivo da Saúde, também designado como Complexo EconômicoIndustrial da Saúde, constitui-se em uma das áreas de maior dinamismo, no entanto, considerada crítica para a área do conhecimento. O setor da saúde possui uma base produtiva de bens e serviços bastante relevante, respondendo por parcela significativa do Produto Interno Bruto (PIB) nas economias emergentes e desenvolvidas, e por associar, inerentemente, as dimensões econômica e social que, juntamente com a ambiental, definem o processo de desenvolvimento. (1)

O Complexo Econômico Industrial da Saúde é caracterizado por setores industriais de base química e biotecnológica (fármacos, medicamentos, imunobiológicos, vacinas, hemoderivados e reagentes) e de base mecânica, eletrônica e de materiais (equipamentos mecânicos, eletrônicos, próteses, órteses e materiais). Esses setores industriais relacionamse com os serviços de saúde (hospitais, serviços de saúde e de diagnóstico) em dinâmica permanente de interdependência e de interação com a sociedade e o Estado, na busca de oferta de serviços e produtos em saúde. (18)

O Ministério da Saúde considera que o aproveitamento do potencial econômico e social do Complexo Econômico Industrial da Saúde, viabilizado, dentre outras estratégias, pela utilização do poder de compra do Estado na área, podem reduzir a vulnerabilidade tecnológica do SUS. (18)

No entanto, mesmo com os avanços da Lei no 10.973/2004 no segmento das atividades de pesquisa e desenvolvimento, dentre eles a possibilidade legal para formalização de parcerias com o setor produtivo privado, ainda permaneciam impedimentos burocráticos a serem suplantados. (8)

Com vistas a viabilizar os avanços consignados na Lei no $10.973 / 2004$, editou-se a Lei no 13.243/2016, que apresentou conceitos e novos princípios para o fomento da inovação no país.

As modificações que merecem destaque são: 1. Dispensa da obrigatoriedade de licitação para compra ou contratação de produtos para fins de pesquisa e desenvolvimento; 2. Regras simplificadas e redução de impostos para importação de material de pesquisa; 3. Permissão para que professores das universidades públicas em regime de dedicação exclusiva exerçam atividade de pesquisa também no setor privado, com remuneração; 4 . Aumento do número de horas que o professor em dedicação exclusiva pode dedicar a atividades fora da universidade, de 120 horas para 416 horas anuais ( 8 horas por semana); 
5. Permissão para que universidades e institutos de pesquisa compartilhem o uso de seus laboratórios e equipes com empresas, para fins de pesquisa (desde que isso não interfira ou conflite com as atividades de pesquisa e ensino da própria instituição); 6. Permissão para que a União financie, faça encomendas diretas e até participe de forma minoritária do capital social de empresas com o objetivo de fomentar inovações e resolver demandas tecnológicas específicas do país e 7. Permissão para que as empresas envolvidas nesses projetos mantenham a propriedade intelectual sobre os resultados (produtos) das pesquisas.

Porém, o êxito dos processos propostos com as alterações está intrinsicamente vinculado à redução do excesso da burocracia imposta por outras leis, como por exemplo, a Lei 8.666/93.

As principais alterações na Lei $n^{\circ} 8.666 / 93$ estão presentes no acréscimo do inciso XX do artigo $6^{\circ}$, dos incisos XXI, XXXI, $\S \S 3^{\circ}$ e $4^{\circ}$ do artigo 24 e do $7^{\circ}$ do artigo 32 , que interferem positivamente no fomento do Complexo Econômico Industrial da Saúde.

O legislador, com o intuito de garantir a correta compreensão dos dispositivos da Lei no 8.666/93, dispõe nos incisos do artigo 6ํㅜㅇ conceitos legais sobre termos considerados relevantes e disciplinados por seus artigos. (21)

Dentre os conceitos, cabe destacar o que foi inserido pela Lei $n^{\circ}=13.243 / 2016$ no inciso $\mathrm{XX}$ do referido artigo, o qual dispõe que:

\section{Artigo 6으...]}

$X X$ - produtos para pesquisa e desenvolvimento - bens, insumos, serviços e obras necessários para atividade de pesquisa científica e tecnológica, desenvolvimento de tecnologia ou inovação tecnológica, discriminados em projeto de pesquisa aprovado pela instituição contratante.

A conceituação do disposto neste inciso tem por objetivo contribuir com a compreensão dos artigos alterados pela Lei $n \times 13.243 / 2016$, os quais refletem no fomento do CEIS.

O inciso XXI do artigo 24 da Lei no 8.666/93 admite, sem restrições, a aquisição ou contratação direta de produto para pesquisa e desenvolvimento, salvo nos casos em que a mesma versar sobre obras e serviços de engenharia, para o qual estabelece a limitação de $20 \%$ do valor previsto na alínea "b" do inciso II do caput do artigo 23. (20) 
Complementando o entendimento, e ampliando o alcance da modificação prevista no inciso XXI do artigo 24, foi acrescentado no mesmo artigo o $\$ 4^{\circ}{ }^{4}$, que destaca que o disposto no inciso I do artigo 9o não se aplica à hipótese prevista no inciso XXI, ou seja, especificamente para esses casos será possível a contratação ou participação do autor do projeto básico e executivo de engenharia na execução do contrato. (20)

No tocante ao incentivo à inovação e pesquisa, a conceituação do inciso XX do artigo 6 , auxilia na compreensão do disposto no inciso XXXI do artigo 24 que dispõe:

\section{Artigo $24[\ldots]$}

XXXI - nas contratações visando ao cumprimento do disposto nos arts. $3^{\circ}, 4^{\circ}, 5^{\circ}$ e 20 da Lei no 10.973, de 2 de dezembro de 2004, observados os princípios gerais de contratação dela constantes. (Incluído pela Lei no 12.349, de 2010)

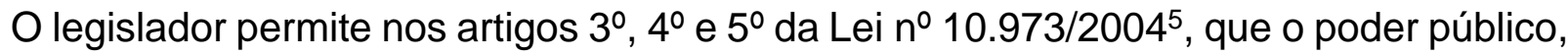
através de alianças estratégicas com o objetivo de garantir a geração de processos que resultem em produtos inovadores, na transferência e difusão de tecnologias, desenvolva projetos de cooperação com empresas nacionais, Instituições Cientificas e Tecnológicas e entidades privadas sem fins lucrativos. (19)

A formulação de alianças estratégicas está imbricada nas diretrizes do Ministério da Saúde, ao tempo em que este compreende que o papel indutor que o Estado desempenha na dinâmica do CEIS, é fundamental para redução da vulnerabilidade tecnológica do SUS. Aliado à estrutura do SUS, que se organiza por instâncias gestoras das três esferas (federal, estadual e municipal), que atuam nas diferentes áreas da saúde, dentre elas na formulação de políticas, no financiamento das ações, na regulação, na prestação de ações e serviços de saúde e, na produção de tecnologias de uso em saúde. (19)

O artigo $3^{\circ}$ estipula que todas as esferas de governo podem estimular e apoiar parcerias estratégicas. Conforme estabelecido em seu Parágrafo único, o apoio poderá contemplar desde redes e os projetos internacionais de pesquisa tecnológicas, até as ações de empreendedorismo tecnológico e de criação de ambiente de inovação, incluindo ainda, incubadoras e parques tecnológicos.

\footnotetext{
${ }^{4}$ Art.24

XXI - para a aquisição ou contratação de produto para pesquisa e desenvolvimento, limitada, no caso de obras e serviços de engenharia, a $20 \%$ (vinte por cento) do valor de que trata a alínea "b" do inciso I do caput do art. 23;

§ 40 Não se aplica a vedação prevista no inciso I do caput do art. 9o à hipótese prevista no inciso XXI do caput

${ }^{5}$ As redações dos artigos $3^{\circ}$, $4^{\circ}$ e $5^{\circ}$ da Lei $10.973 / 2004$ foram alteradas pela Lei $n^{\circ}=13.243 / 2016$
} 
Neste contexto, os estímulos previstos no artigo 3ํ, no âmbito da despesa pública, podem se concretizar em contribuições e subvenções destinadas a instituições públicas e privadas. (21)


poderão mediante remuneração e por prazo determinado, compartilhar seus laboratórios, equipamentos, instrumentos, materiais e demais instalações com microempresas e empresa de pequeno porte, bem como, permitir a utilização destes por empresas nacionais e organizações de direito privado sem fins lucrativos.

O compartilhamento está atrelado à consecução de atividades de incubação, sem prejuízo da atividade finalística das Instituições Cientificas e Tecnológicas e desde que tal permissão não interfira diretamente na sua atividade fim nem seja conflitante. Compartilhar ou permitir o uso somente serão permitidos quando as atividades estejam voltadas respectivamente à inovação tecnológica ou à pesquisa. (20) (21)

O artigo $5^{\circ}$ autoriza a União e suas entidades a participar minoritariamente do capital de empresa privada de propósito específico que vise ao desenvolvimento de projetos científicos ou tecnológicos para obtenção de produtos inovadores. Tais empresas são juridicamente denominadas como Sociedade de Propósito Específico (SPE). (20) (21)

Neste ponto insta importante discorrer sobre as características da Sociedade de Propósito Específico. Trata-se de uma sociedade que se destina a um objeto específico e determinado, e com o advento da Lei n 11.079/2004, é comum verificar sua aplicação no âmbito das Parcerias Públicas Privadas. A SPE pode ser definida como uma estrutura negocial agregadora de interesses e recurso de duas ou mais pessoas, naturais ou jurídicas, naturais ou estrangeiras para a consecução de empreendimento de objeto específico e determinado mediante a constituição. (21)

O artigo 20 da Lei no 10.973/2004, após alteração da Lei no 13.243/2016, passa a prever que órgãos e entidades da Administração poderão contratar diretamente Instituições de Ciência e Tecnologia e entidades privadas sem fins lucrativos ou empresas, isoladamente ou em consórcios voltados para as atividades de pesquisa. Embora o inciso XXXII do artigo 24 da Lei no 8.666/93, tenha sido incluído pela Lei no 12.715/2012, não estando vinculado as alterações oriundas da Lei de Inovação, seu conteúdo é relevante para o fomento do Complexo Econômico Industrial da Saúde. 
A Lei no 8.080/90 nos incisos VI e X do artigo 6º estipula que a formulação da política de medicamentos, equipamentos, imunobiológicos, a participação na produção, assim como, o estímulo ao desenvolvimento científico e tecnológico, são campos de atuação do Sistema Único de Saúde (SUS).

Ainda no âmbito da Lei no 8.080/90, o artigo 46 prevê que o SUS estabelecerá mecanismos de incentivos à participação do setor privado no investimento em ciência e tecnologia e estimulará a transferência de tecnologia das universidades e institutos de pesquisa aos serviços de saúde nos Estados, Distrito Federal e Municípios, e às empresas nacionais. (17)

De acordo com o Decreto n 7.807/2012, a direção nacional do SUS definirá quais são os produtos estratégicos para o SUS, em conformidade com as recomendações expedidas pelo Grupo Executivo do Complexo Industrial da Saúde (GECIS), criado pelo Decreto de 12 de maio de 2008 (22). O GECIS, coordenado pelo Ministério da Saúde, atua sob as diretrizes e estratégias de desenvolvimento do Governo Federal para a área da saúde, visando o fortalecimento do complexo produtivo e de inovação em saúde.

Os produtos estratégicos para o SUS são aqueles necessários às ações de promoção, prevenção e recuperação da saúde, com aquisições centralizadas ou passíveis de centralização e cuja produção nacional e de seus insumos farmacêuticos ativos ou componentes tecnológicos críticos são relevantes para o Complexo Econômico Industrial da Saúde. (22)

A possibilidade de contratação de transferência de tecnologia de produtos estratégicos para o SUS é uma situação peculiar, considerando que tais produtos são definidos por Portaria editada pela gestão nacional do SUS, é possível presumir que a tecnologia corresponde ao conhecimento técnico ou científico empregado na criação desses produtos. (21)

Insta importante destacar, que o artigo $3^{\circ}$ e os incisos XXV, XXXI, XXXII do artigo 24, alterados pela Lei $n^{0} 13.273 / 2016$ e do inciso $V$ do artigo 57 da Lei no 8.666/93, subsidiam as Parcerias para o Desenvolvimento Produtivo (PDP), instrumento utilizado para o fomento do Complexo, que envolve a cooperação entre instituições públicas e entre instituições públicas e entidades privadas para desenvolvimento, transferência e absorção de tecnologia, produção, capacitação produtiva e tecnológica do País em produtos estratégicos para atendimento às demandas do SUS. 
As prioridades anuais para apresentação de propostas de projeto de Parcerias para o PDP são pautadas na lista de produtos estratégicos para o SUS. O processo de atualização da lista é coordenado pela Secretaria de Ciência, Tecnologia e Insumos Estratégicos (SCTIE) junto às demais secretarias do Ministério da Saúde, quais sejam: a Secretaria de Atenção à Saúde (SAS) e a Secretaria de Vigilância em Saúde (SVS), órgãos de Governo que integram o GECIS e Entidades do Conselho de Competitividade do setor. (16)

O artigo 32 da Lei ำ 8.666/93, que desobriga a apresentação em licitações da documentação de habilitação, no todo ou em parte, para a contratação de produto para pesquisa e desenvolvimento, desde que para pronta entrega ou até o valor previsto na alínea "a" do inciso II do artigo 23.

Este artigo visa fomentar a aquisição de produtos de pesquisa e desenvolvimento, garantindo celeridade e desburocratização das contratações, evitando assim que ritos processuais lentos causem prejuízos aos processos de incorporação. (16)

As alterações na Lei n 8.666/93, contribuem para a implementação de projetos de inovação e desenvolvimento, impulsionados pelo Estado como indutor do desenvolvimento científico, tecnológico e produtivo na Saúde do Brasil.

Com vistas ao fomento do Complexo Industrial da Saúde, o Estado utiliza de instrumentos como: 1. Uso do poder de compra do Estado; 2. Parcerias para o Desenvolvimento Produtivo; 3. Programa para o Desenvolvimento do Complexo Industrial da Saúde (PROCIS); 4. Compensação tecnológica - Acordo de Compensação nº 001/2015; 5. Programa Pesquisa para o SUS (PPSUS); 6. Incentivos Fiscais: Isonomia Tributária e 7. Incorporação de Tecnologias.

É possível perceber que 60\% dos instrumentos citados no parágrafo anterior, decorrem de compras públicas, demonstrando que neste aspecto as alterações na Lei nํ 8.666/93 são de suma importância para o êxito desses processos de fomento do CEIS.

\section{Considerações finais}

Considerando o estudo realizado, foi possível identificar que as disposições contidas na Lei nº 13.243/2016 exerceram influência positiva no fomento do setor produtivo da saúde.

As alterações na Lei no 10.973/2004, respaldadas pela Emenda Constitucional no 85/2015, atuaram positivamente, na medida em que permitiram flexibilizar as relações 
público-privadas com o intuito de viabilizar o aumento da taxa de inovação e a redução da dependência tecnológica do país.

Há que se considerar que a flexibilização na contratação, na formalização de parcerias com o setor produtivo da saúde, bem como a alocação de recursos para desenvolvimento de tecnologia ou inovação tecnológica são aspectos relevantes para o fomento do Complexo Econômico Industrial da Saúde, principalmente por estabelecer dispositivos que diferenciam a inovação e a pesquisa, da regulação imposta para contratações gerais.

Conforme destacado, embora a saúde se configure como um direito social, elemento essencial do Estado de Bem-Estar Social, na perspectiva da economia, por contar com uma base produtiva dinâmica e inovativa de bens e serviços, pode ser considerada como um bem econômico com acumulação de capital.

Neste contexto, os incentivos para o desenvolvimento dispostos na Lei ํㅜ 13.243/2016 e as alterações de outras nove leis, potencializaram as ações do complexo no sentido de mobilizar junto ao setor produtivo, tecnologias relevantes que possibilitem a inserção competitiva do país no contexto da econômica global, bem como, da área da saúde na pauta do desenvolvimento nacional.

A saúde, por possuir sistemas complexos de inovação, demandam de crescentes investimentos em capacitação, pesquisa, projeto de desenvolvimento e inovação, a fim de se obter casos de inovações exitosas. A implementação destes projetos de desenvolvimento e inovação, são impulsionados pelo Estado, por intermédio de mecanismos e instrumentos previstos nos incisos I a XII do $\S^{2}$ do artigo $19^{6}$ da Lei $n^{\circ}$ 10.973/2004, como indutor do desenvolvimento científico, tecnológico e produtivo na Saúde do Brasil.

\footnotetext{
${ }^{6}$ Art. 19.

§ 2ㅇ-A. São instrumentos de estímulo à inovação nas empresas, quando aplicáveis, entre outros

I - subvenção econômica

II - financiamento;

III - participação societária;

IV - bônus tecnológico;

$\mathrm{V}$ - encomenda tecnológica;

$\mathrm{VI}$ - incentivos fiscais;

VII - concessão de bolsas

VIII - uso do poder de compra do Estado

IX - fundos de investimentos;

$X$ - fundos de participação;

$\mathrm{XI}$ - títulos financeiros, incentivados ou não

XII - previsão de investimento em pesquisa e desenvolvimento em contratos de concessão de serviços públicos ou em regulações setoriais.
} 


\section{Referências}

1. Metten A, Costa LS; Gadelha CAG; Maldonado J. A introdução do complexo econômico industrial da saúde na agenda de desenvolvimento: uma análise a partir do modelo de fluxos múltiplos de Kingdon. Revista de Administração Pública. 2015; 49(4):915936. Disponível em: http://www.scielo.br/scielo.php?script=sci arttext\&pid=S0034$\underline{76122015000400915 \& \operatorname{lng}=p t \& t \mid n g=p t}$ [Acesso em 10.out.2017]

2. Viana AL, Silva HP, Elias PEM. Economia política da saúde: introduzindo o debate. Divulgação em Saúde para Debate. 2007; 37:7-20.

3. Cassiolato J, Lastres HMM. Inovação e sistemas de inovação: relevância para a área de saúde. Revista Eletrônica de Comunicação, Informação \& Inovação em Saúde. 2007; 1(1):153-162. Disponível em:

https://www.researchgate.net/publication/250234867 Inovacao e sistemas de inovacao relevancia para a area de saude. [Acesso em 18.set.2017].

4. Botelho AJJ, Alves AS. As lacunas de inovação em Saúde no Brasil: entre a produção de ciência e tecnologia na saúde. In: Costa LS, Bahia L, Gadelha CAG, (orgs). Saúde, Desenvolvimento e Inovação. Rio de Janeiro: CEPESC; 2015.

5. Tigre PB, Nascimento CVF do. Teorias da inovação e trajetórias tecnológicas na saúde. In: Costa LS, Bahia L, Gadelha CAG (orgs). Saúde, Desenvolvimento e Inovação. Rio de Janeiro: Cepesc-IMS/UERJ-Fiocruz; 2015.

6. Tenório M, Arantes Mello G, D’Ávila Viana A L, Políticas de fomento à ciência, tecnologia e inovação em saúde no Brasil e o lugar da pesquisa clínica. Ciência \& Saúde Coletiva. 2017; 22(1):1441-1454. Disponivel em: http://www.redalyc.org/articulo.oa?id=63050935006 [Acesso em 24.set.2017].

7. Ferreira VF. Expectativas geradas com o novo Marco Legal da Ciência e Tecnologia e Inovação. Revista Virtual de Química. 2016; 8(3):559-560. Disponível em: http://rvq.sbq.org.br/imagebank/pdf/v8n3a01.pdf . [Acesso em 8.set.2017].

8. Sucsú $A B$, Silveira M. Avanços e retrocessos no marco legal da ciência, tecnologia e inovação: mudanças necessárias. Revista Ciência \& Cultura. 2016; 68(2):04-05. Disponível em: http://cienciaecultura.bvs.br/scielo.php?script=sci arttext\&pid=S0009$\underline{67252016000200002 \& \mathrm{Ing}=p t \& n r m=i s o}$ [Acesso em 21.set.2017].

9. Maldonado J, Valadares E, Costa LS E Gadelha CAG. Nichos estratégicos da inovação em saúde nos segmentos de materiais e equipamentos de saúde. In: Costa LS, Bahia L, Gadelha CAG (orgs). Saúde, Desenvolvimento e Inovação. Rio de Janeiro: CepescIMS/UERJ-Fiocruz; 2015. 
10. Novaes HMD, Soares PC. Avaliação de tecnologias em saúde: técnicas, práticas e políticas. In: Costa LS, Bahia L, Gadelha CAG, (orgs.). Saúde, Desenvolvimento e Inovação. Rio de Janeiro: Cepesc-IMS/UERJ-Fiocruz; 2015.

11. Padula R, Noronha GS de, Mitidieri TL. Complexo Econômico-Industrial da Saúde, segurança e autonomia estratégica: a inserção do Brasil no Mundo. In: Gadelha CAG, Gadelha P, Noronha JC et al (orgs). Brasil Saúde Amanhã: complexo econômico-industrial da saúde. Rio de Janeiro: Fiocruz; 2016.

12. Brasil. Constituição da República Federativa do Brasil, 8 de outubro de 1988. Brasília: Senado Federal, 2008.

13. Brasil. Lei $n^{0} 13.243$, de 11 de janeiro de 2016. Dispõe sobre estímulos ao desenvolvimento científico, à pesquisa, à capacitação científica e tecnológica e à inovação e altera a Lei no 10.973, de 2 de dezembro de 2004, a Lei no 6.815, de 19 de agosto de 1980, a Lei no 8.666, de 21 de junho de 1993, a Lei no 12.462, de 4 de agosto de 2011, a Lei no 8.745, de 9 de dezembro de 1993, a Lei no 8.958, de 20 de dezembro de 1994, a Lei no 8.010, de 29 de março de 1990, a Lei no 8.032, de 12 de abril de 1990, e a Lei no 12.772, de 28 de dezembro de 2012, nos termos da Emenda Constitucional no 85, de 26 de fevereiro de 2015. Disponível em: http://www.planalto.gov.br/CCIVIL 03/ Ato20152018/2016/Lei/L13243.htm [Acesso em 1.set.2017].

14. Brasil. Lei no 8.666, de 21 de junho de 1993. Regulamenta o art. 37, inciso XXI, da Constituição Federal, institui normas para licitações e contratos da Administração Pública e dá outras providências. Disponível em:

http://www.planalto.gov.br/ccivil 03/Leis/L8666cons.htm [Acesso em 1.set.2017].

15. Brasil. Lei no 10.973, de 2 de dezembro de 2004. Dispõe sobre incentivos à inovação e à pesquisa científica e tecnológica no ambiente produtivo e dá outras providências. Disponível em: http://www.planalto.gov.br/ccivil 03/ Ato2004-2006/2004/Lei/L10.973.htm [Acesso em 20.set.2017].

16. Ministério da Saúde. Parceria para o Desenvolvimento Produtivo. Disponível em: http://portalms.saude.gov.br/ciencia-e-tecnologia-e-complexo-industrial/complexoindustrial/parceria-para-o-desenvolvimento-produtivo-pdp [Acesso em 10.out.2017].

17. Ministério da Saúde. Programa para o Desenvolvimento do Complexo Industrial da Saúde (PROCIS). Disponível em: http://u.saude.gov.br/index.php/o-ministerio/principal/leiamais-o-ministerio/581-sctie-raiz/deciis/l2-deciis/12091-programa-para-o-desenvolvimentodo-complexo-industrial-da-saude-procis [Acesso em10.out.2017]

18. Ministério da Saúde. O Complexo Econômico Industrial da Saúde. Disponível em: http://u.saude.gov.br/index.php/o-ministerio/principal/leia-mais-o-ministerio/579-sctieraiz/deciis/23782-o-complexo-economico-industrial-da-saude-ceis [Acesso em 10.out.2017]. 
19. Torres RCL, Alves AS. Leis de Licitações Públicas Comentadas. Rio de Janeiro: Jus Podivm, 2017.

20. Fernandes, JUJ. Contratação Direta sem Licitação. Belo Horizonte: Fórum, 2016.

21. Bittencourt, S. Licitação. Belo Horizonte: Fórum, 2016.

22. Ministério da Saúde. O Complexo Econômico Industrial da Saúde. Grupo Executivo do Complexo Industrial da Saúde. Disponível em: http://portalms.saude.gov.br/ciencia-etecnologia-e-complexo-industrial/complexo-industrial/grupo-executivo-do-complexoindustrial-da-saude-gecis [Acesso em 12.out.2017].

23. Nazareno C. As mudanças promovidas pela Lei oㅜ 13.243, de 11 de janeiro de 2016 (novo Marco Legal de Ciência, Tecnologia e Inovação) e seu impactos no setor. Brasília: Consultoria Legislativa da Câmara dos Deputados, 2016. Disponível em: file:///C:/Users/marco/Downloads/mudan\%C3\%A7as\%20 promovidas nazareno.pdf [Acesso em 10.nov.2017].

\section{Como citar este artigo:}

Pereira AS. Complexo Econômico Industrial da Saúde: os reflexos jurídicos dos estímulos ao desenvolvimento tecnológico previstos na Lei oㅜ13.243/2016. Revista Cadernos Ibero-Americanos de Direito Sanitário. 2018 jan./mar, 7(1):96-110. 